\section{INFRAESTRUCTURA DE LO COMÚN EN TIEMPOS DE EMERGENCIA. RECONSTRUCCIÓN EN CONSTITUCIÓN Y LLICO'}

María Prieto Peinado²

\section{INFRASTRUCTURE FOR THE COMMON GOOD IN TIMES OF EMERGENCY. RECONSTRUCTION IN CONSTITUCIÓN AND LLICO}

\author{
María Prieto Peinado
}

\section{Abstract}

This paper aims to provide an alternative contribution through the construction of infrastructure for the common good as an opportunity to improve collective spaces that could be included in post-earthquake reconstruction plans for urban environments. This research is based on the project entitled "Post-27F Earthquake and Tsunami in Southern Chile: Urban Regeneration", conducted in Constitución and Llico over the period 2013 to 2015. This study analyzes the key elements found in the spontaneous spatial appropriation processes that took place in emergency 
indagando en el carácter espacial y en la movilidad, y en comparación con los condominios de nueva construcción, a fin de distinguir las tácticas espaciales para la mejora del barrio y la construcción de la ciudad.

PALABRAS CLAVE: RECONSTRUCCIÓN, POSCATÁSTROFE, BARRIO, MOVILIDAD, CIUDAD

Recibido: 01-06-2016

Aceptado: 11-12-2017 settlements and explores the special nature and mobility characteristics of this phenomenon. These elements are compared with new buildings in order to identify spatial-based strategies that may contribute to the improvement of neighborhoods and the construction of the city.

KEYWORDS: RECONSTRUCTION, POST-DISASTER, NEIGHBORHOOD, MOBILITY, CITY.

Received: 01-06-2016

Accepted: 11-12-2017

1 This research was supported by the Inclusive-Habitat cooperation group and funded by the University of Seville.

2 Spain. University of Seville. Email: mariaprieto12@gmail.com.

2 España. Universidad de Sevilla. Correo electrónico: mariaprieto12@gmail.com. 


\section{Introducción}

La presente investigación está basada en el proyecto "Reconstrucción tras el terremoto / tsunami 27F en el sur de Chile: regeneración de barrios", que contó con la ayuda de la Universidad de Sevilla y se realizó en colaboración con el Instituto de la Vivienda de la Universidad de Chile. El proyecto pretendía un seguimiento al proceso de reconstrucción acometido por el Gobierno de Chile mediante el Plan de Reconstrucción del Ministerio de Vivienda y Urbanismo PR_MINVU³.

En su primera fase (2013) surgió como apoyo al proyecto "Observatorio de la Reconstrucción" $(\mathrm{OR})^{4}$ y fue dirigido a las localidades costeras de Constitución y del sector de Llico de la comuna de Arauco, y a las localidades de interior de Cauquenes y Curicó. Se trató de una investigación apoyada en la cooperación horizontal, centrada principalmente en el empoderamiento de la población y con el fin de indagar una mejor y más integrada respuesta para la reconstrucción, teniendo en cuenta factores como el impacto urbano.

3 Plan de Reconstrucción Sustentable PRES http://www.minvu. cl/opensite_20111122105648.aspx.

4 Proyecto Observatorio de la Reconstrucción (OR) desarrollado por el INVI, subvencionado por la institución Valentín Letelier (VID) 2010 entregado por la Vicerrectoría de Extensión de la Universidad de Chile.
Con posterioridad y en correspondencia con la pretensión inicial, se planteó la segunda fase (2014-2015), centrada en profundizar el estudio en la localidad de Constitución y Llico, y con el objetivo definitivo de investigar cómo recuperar la memoria destruida del barrio desde sus relaciones urbano-espaciales y bajo una iniciativa metodológica comparativa, orientada hacia la búsqueda cualitativa de claves espaciales en los procederes espontáneos de creación de espacios para la colectividad y, dentro del proceso mismo del propio PR_MINVU, (procesos como los desarrollados en las aldeas de emergencia ${ }^{5}$ entre otros). A partir de aquí, se proponen como resultado de la investigación las diversas claves proyectuales a considerar en el desarrollo de un proyecto de infraestructura de lo común.

Seguidamente, se argumentan los conceptos básicos que a modo de variables, permitirán comprender el ámbito en el que se mueve la investigación. Conceptos como colectividad, bienestar, calidad de vida, infraestructura o lo común, y otros como el valor de los procesos espaciales espontáneos y la ciudad de las tácticas o ciudad del margen,

5 Viviendas agrupadas para responder a la emergencia habitacional. 
que contribuirían a justificar los intereses de la investigación.

Tras la catástrofe se hace evidente la necesidad de desplegar asistencias urgentes con la puesta en marcha de un protocolo de emergencia a corto plazo (escala emergencia), pero no obstante, a medio plazo (escala reconstrucción), será necesario desarrollar un Plan de Reconstrucción Integral ${ }^{6}$ que propusiera recuperar, entre la gravedad de las pérdidas, el bienestar ${ }^{7}$, aun cuando antes no lo hubiera habido, como oportunidad de mejora y como potencial de la otra cara de la catástrofe; para alcanzar condiciones de igualdad recomendables en un bienestar urbano ${ }^{8}$ a medio y largo plazo.

Es importante no perder de vista este objetivo de bienestar9, entendido en el sentido de "calidad de vida” (Levi y Anderson, 1980; Alguacil, 2000), incluyendo tanto al bienestar individual como al colectivo. La calidad de vida depende de muy diversos condicionantes 10 y estos a su vez dependen de las diversas disciplinas que los estudien. En este

6 Ver Plan de reconstrucción, 2010.

7 Entendido como la satisfacción en la provisión de los bienes y servicios definidos como básicos (Hernández Aja, 2009).

8 Define a la concreción del bienestar sobre el espacio urbano (relacionado con la calidad ambiental e identidad, entre otras).

$9 \quad$ Según el preámbulo de la Constitución de la Organización Mundial de la Salud (OMS) (Conferencia Sanitaria Internacional firmado 1946), la salud física se concibe como "estado de total bienestar, físico, mental y social".

10 Condicionantes que proceden de satisfacer las necesidades humanas básicas y universales (Alguacil, 2000, p. 57). caso se analiza el condicionante urbano-espacial de carácter transitorio y cambiante, resultante del proceso de transformación que sobreviene a la catástrofe, especialmente el relacionado con lo que denominamos espacio intermedio, por situarse entre lo privado y lo público.

La calidad de vida no solo se mide con indicadores objetivos $^{11}$, sino que también se mide con indicadores subjetivos, como la satisfacción, que tiene que ver con la necesidad y con lo deseable y en este caso, con la recuperación de la identidad y con el arraigo, reproduciendo, en la medida de lo posible, el antes de la catástrofe. Toda esta cuestión nos lleva de nuevo a recabar en la cualidad de los contextos urbanos en su más amplio sentido, como elemento principal en la recuperación de la calidad de vida colectiva que repercutirá en el bienestar individual y viceversa.

Atendiendo a la matriz de necesidades y satisfacciones de Max-Neef y Capaur (1986, citado en Alguacil, 2000, p. 59) se observan ciertas categorías

11 Apoyados sobre todo en estadísticas cuantitativas que relacionan el nivel de empleo, salud, educación o vivienda, entre otros. 
espaciales relacionadas entre ellas, según nuestro entender, y relacionadas con la necesidad humana que satisfacen o debieran satisfacer. Podríamos entresacar las siguientes: espacio vital seguro, espacio de unión entre personas, barrio (espacios para la participación), espacios para la expresión, espacios de encuentros y paisajes, marcos de vida diaria (espacios para la cotidianeidad), plasticidad espacio-temporal (espacio para la apropiación). Cada una de ellas contribuye a satisfacer necesidades como protección, afecto, participación, creación, recreo, identidad y libertad, respectivamente. Por lo tanto, se deduce que recuperar la calidad de vida de la población en estado de emergencia o no, pasa por proyectar esta red de espacios que permitan alcanzar cada necesidad y en definitiva conseguir el desarrollo de las relaciones colectivas para restituir así el sistema de valores propios.

Las acciones imperantes acometidas en los últimos planes de reconstrucción postcatástrofe $^{12}$, han priorizado la restitución de la vivienda; subsidiando y resolviendo de esta manera la escala de lo privado, que sin querer menosprecian el esfuerzo que ha supuesto el reto chileno y sus resultados, creemos importante no olvidar las relaciones que permiten construir el sentido de la vivienda

12 Plan de Reconstrucción-MINVU Gobierno de Chile, 2010. Plan de Reconstrucción Japón, 2011. L'Aquila, Italia, 2009; Plan de Reconstrucción, Perú, 2007; Plan de Revitalización de Kobe (KRP), 1995. más allá del objeto en sí y por tanto, buscar propuestas integradoras de objetivos urbanos más exigentes. La cualidad del espacio doméstico se construye en la necesidad del barrio habitable y este es parte y viene condicionado por la equidad, comunicación y sociabilidad entre sus habitantes. La construcción del barrio está potenciada por la formalización de la vivienda, pero no nace de la exclusiva existencia de la misma. La cotidianeidad de un barrio no se restaura como inercia de la solución habitacional a las familias damnificadas exclusivamente (MINVU, 2009, p. 90-93).

Desde la arquitectura (al igual que desde otras disciplinas) se dispone de las estrategias inclusivas necesarias para la construcción física y emocional del espacio colectivo del barrio. Con la denominación espacio colectivo o espacios para la colectividad, se hace referencia a espacios urbanos donde se desarrolla la acción colectiva (Melucci, 1996) y esta va más allá de la suma de comportamientos individuales agregados. Estos espacios forman un territorio complejo que habla de costumbre, necesidad, emoción, comunicación, conversación ${ }^{13}$ y vida cotidiana (Lefebvre, 2002; Certeau, 2000), se podría decir que son o deben ser espacios solidarios que

13 Casarino argumenta: “Asimismo, estimo que 'conversación' es una palabra que nos lleva sin rodeos a la problemática de lo común" (Negri y Casarino, 2012). 
permitan la cercanía de los cuerpos, facilitando la apropiación para devolver la identidad, que no solo va a definirnos culturalmente sino también nos proteger, al concedernos la seguridad y permitirnos la pertenencia al grupo.

La acción colectiva para existir necesita de un espacio que permita el encuentro, un espacio accesible y comunicado, con la escala apta para la relación humana, un espacio que dé cabida a lo emotivo, construido por los vecinos o conciudadanos, un espacio sano cualificado naturalmente, con vegetación, luz y soleado, en definitiva un espacio que facilite la construcción de lo común.

Sin duda la necesidad de dotación de equipamientos convencionales; columpios, bancos o farolas, supone un primer paso, pero sería ingenuo pensar que tal complejidad se resuelve simplemente con estas dotaciones. En paralelo se deben dar las condiciones espaciales específicas para la buena práctica de la colectividad, una práctica que pueda alcanzar los niveles de satisfacción deseados.

En este sentido, el espacio colectivo es urbano, por lo que sería interesante y necesario abordar el concepto de ciudad con el cual se trabaja. La ciudad es entendida como un sistema de complejidad organizada (Castells, 2000) constituido por la superposición de diferentes capas, capas físicas y experienciales $^{14}$, que definen tanto lo edificado, como y sobre todo la experiencia, ya sean relaciones colectivas o meras interacciones urbanas (Simmel, 1986; Delgado, 2008).

Para ello, se hace necesario fijar la mirada en la antesala del espacio colectivo construido (programado o apropiado), donde se encontraría la categoría de la infraestructura, ya que según Allen (1998) la infraestructura es entendida como la "construcción del lugar mismo. Las infraestructuras preparan el terreno para construcciones futuras", comprendiendo entre sus principales modos de operación "la provisión de servicios para sustentar futuros programas [y] el establecimiento de redes de movimiento, comunicación e intercambio" (Allen, 1998). De ello se deduce la capacidad de la que se dota la infraestructura para reconocer y favorecer la naturaleza colectiva de la ciudad, pudiendo afirmar que toda infraestructura conlleva un destino final que beneficia a una colectividad. En este sentido, si aplicamos la capacidad de la infraestructura a la construcción de una red de barrio, que posibilite el desarrollo social e identitario en el mismo, que preserve sus tradiciones y permita aperturas

14 Al hablar de capas nos referimos a las diferentes condiciones que construyen la ciudad, como la histórica, la institucional, económica, medioambiental, morfológica, entre otras y también podemos distinguir entre la ciudad de los deseos, la del consumo, la del control, o la del miedo, por ejemplo. 
a nuevas formas de habitar la ciudad, estaremos en lo que se denomina en la investigación infraestructura de lo común, intentando con ello enunciar sobre todo, cierto proceder como sistema de dinámicas colectivas para la construcción del barrio y en consecuencia, la ciudad.

Encontrar claves contemporáneas para la articulación del proyecto infraestructura de lo común requiere indagar en experiencias desarrolladas en condiciones de libertad y cambio (espacial), y para ello se entiende necesario trabajar en la condición de límite (Trías, 1991), desde el terreno de la incertidumbre, porque se entiende que es desde esta condición de libertad desde donde se pueden construir las apropiaciones más verdaderas de la condición humana,

"tenemos la necesidad de lugares de habitar -pero estos no pueden ser espacios cerrados que contradicen el tiempo del territorio donde, nos guste o no, vivimos [...] deberán ser unos espacios de la 'relatividad general' [...] deben poderse 'deformar' o transformar durante su movimiento [...] La distribución de la materia en estos espacios mutará así constantemente e imprevisiblemente" (Cacciari, 2002, p. 4-7).

La condición de límite buscada en los procesos espaciales espontáneos de la reconstrucción, nos lleva a la ciudad del margen (Prieto, 2015), donde se encuentra la informalidad como ciudad transitoria, ciudad disidente o fuera de la planificación, con las atribuciones de "la ciudad de las tácticas"(Certeau,
2000), para poder encontrar procesos espaciales espontáneos formuladores de nuevos modos de habitar lo común (Gatti, 1999) y donde prevalece la relación frente a la formalización, generándose fuertes redes colectivas.

Esta opción no deslegitima las propuestas planificadoras recogidas en el PR-Constitución por ejemplo, al reconstruir conjuntos edilicios al servicio del interés público en el centro urbano como área prestigiosa de la ciudad, porque se entiende la revalorización que supone para la ciudad misma, en cuanto atractor de visitantes y consumidores. Pero de igual modo, se comprende la urgencia de superar una economía de mercado que invierte los objetivos en la producción de ciudad y nos lleva a una centralización sumidero de espacios construidos relevantes (teatros, cines o casas de la cultura entre otros). Estas acciones terminan creando una centrolandia, sustituyendo la ciudad de la cotidianeidad por la espectacularización de la misma (Debord, 2010) y potenciando la ciudad para el consumo, que convierte en valor de mercado lo que antes era tan solo cultura, patrimonio o tradición (Soja, 2008; Harvey, 1998; Jacobs, 2011). Es por esto que no sorprende que las estrategias planteadas en tiempos de catástrofes hagan hincapié en principios que garanticen una revalorización segura, aunque, de igual modo, no hay que olvidar el perjuicio que esta circunstancia provoca a largo plazo, desfavoreciendo radicalmente el crecimiento urbano equilibrado e igualitario. Por lo tanto, 
se hace inaplazable resolver las periferias, en su más amplio sentido, pensar la escala intermedia de cercanía territorial y de relación entre cada una de las colectividades barriales que habitan la ciudad.

Se trata de resolver la interconexión dentro y fuera del barrio, movilidad sostenible (Hall, 1999, p. 173-185), porque de ella dependerá en gran medida la igualdad de oportunidad de sus habitantes. La producción de periferias discontinuas promueve la necesidad de transporte privado y el aislamiento, mientras una infraestructura de lo común debería permitir la práctica de un urbanismo de proximidad (Frank \& Pivo, 1994, p. 44-52).

La infraestructura de lo común se piensa por tanto, como la previsión que posibilita nuevos códigos espaciales, temporales y materiales en la habitabilidad urbana contemporánea. Para ello, se hace imprescindible y sobre todo en el caso que nos ocupa, tener presente los intereses de la ciudadanía al tiempo que propiciar su participación en el espacio urbano. Así pues, se propone una investigación abierta que implica a la población damnificada con el fin de que sientan suyo el devenir del estudio y con ello, la capacidad de apropiación de la propuesta de infraestructura. "Apropiarse de un lugar no es únicamente hacer de él una utilización reconocida, es establecer con él una relación, integrarlo a las vivencias propias, enraizarse, dejar en él la huella propia y convertirse en actor de su propia transformación" (Chombart de Lauwe, 1976).

En definitiva, la infraestructura de lo común se propone como construcción de una red de espacios para la acción colectiva, apoyada en una arquitectura que actúe como dispositivo y permita al poblador la apropiación del lugar para una mejor comunicación con sus iguales, o para la construcción de una nueva identidad o la recuperación de la que fue, "flexible a la apropiación del usuario, porque lo común surgirá tanto del potencial de este espacio como del acto común en sí" (Negri y Casarino, 2012, p. 18).

\section{Metodología}

La investigación se aborda desde un enfoque fenomenológico ${ }^{15}$ que indaga en la experiencia cotidiana, la existencia de posibles estrategias, motivaciones, emociones y simbolizaciones que construyen el espacio de lo común. Explora procederes espontáneos descritos por sus protagonistas, tratándose de un estudio cualitativo (Taylor y Bogdan, 1994)

15 “El enfoque fenomenológico tiene como foco entender el significado que tienen las experiencias para las personas que serán estudiadas...buscar entender una situación tal como es construida por los participantes" (Maykut y Morehouse, 1999). 
a través de la observación directa y apoyado en las técnicas de entrevista coloquial y acompañamientos, también se sirve de fotografías, cuadernos de campo, mapeos y representaciones diversas. Al extraer la información se trata de no reducir la complejidad de la realidad observada (Anguera, 1998) y poder encontrar la estructura dinámica colectiva de esta población en los momentos pos catástrofe.

Con un diseño de investigación emergente (Maykut y Morehouse, 1999) el estudio ha seguido un proceso de reformulación adaptándose a las reflexiones resultantes de la información extraída en la primera fase (2013) para en una segunda fase (2014-15), centrar el ámbito de estudio en Constitución y el sector de Llico de la comuna de Arauco. De esta manera, junto con redirigir el foco de la investigación al estudio de la movilidad, tanto desde lo cualitativo como desde aspectos cuantitativos (medios de transportes y comunicación existentes, accesibilidad, entre otros), se examina la habitabilidad de los entornos de la Reconstrucción.

El análisis de datos es inductivo (Maykut y Morehouse, 1999). Se trabaja la comparación crítica entre situaciones en sectores programados, como los condominios de nueva construcción planificados por el
PR_MINVU y en sectores no programados, como las aldeas de emergencia, donde la precariedad se acompaña de la capacidad y libertad para la apropiación y la construcción de lugares colectivos singulares. Tanto los pobladores participantes, como los contextos urbanos elegidos han sido los más representativos en relación a sus vivencias directas con los procesos espontáneos dados en la Reconstrucción. De igual manera los informantes han sido elegidos por su cercanía, conocimiento e implicación en el proceso de reconstrucción y en ambas fases se ha contado con el apoyo de investigadores del INVI UChile.

La investigación ha contado con una búsqueda bibliográfica relacionada (con la aportación de datos cuantitativos y cualitativos) y con encuentros a nivel de instituciones vinculadas, locales y gubernamentales, como por ejemplo, Ministerio de Vivienda y Urbanismo del Gobierno de Chile MINVU y la Municipalidad de Constitución, investigadores de la Facultad de Arquitectura y Urbanismo de la Universidad de Chile FAU-UChile, representantes y arquitectos del Colegio de Arquitectos de Chile, así como con ONGs locales, destacando los encuentros con la ONG Surmaule en Talca y con el Movimiento Nacional por una Reconstrucción Justa en Constitución. 


\section{Constitución y Llico. Emergencia de lo común}

Se analizan dos cuestiones del proceso de reconstrucción en la localidad de Constitución ${ }^{16}$ y en el sector de Llico, comuna de Arauco ${ }^{17}$. Una, el proceso espacial de apropiaciones en las aldeas de emergencia, La Poza y Antofa en Constitución y Nueva Esperanza en Llico. Otra, la movilidad sostenible, además del proceso espacial, en los nuevos o no, barrios periféricos apoyados por la reconstrucción, barrios como, Vista Hermosa, Las Cumbres, Quinta Gaete y Bicentenario en Constitución o Nueva Esperanza en Llico.

A pesar de la diferencia de escala y contexto entre Constitución y Llico que, a priori, podría desaconsejar el estudio conjunto entre ambas. Por el contrario, es esta diferencia la que permite evidenciar cuestiones como la inversión relativa realizada en la reconstrucción (pública o privada), cuando el interés valora otros objetivos por encima de conseguir de manera equitativa, la calidad de vida de

16 Comuna costera en la desembocadura del río Maule, VII región, de aproximadamente 46.000 habitantes, Antiguamente dedicada a la pesca, con la plantación de pino y eucalipto posteriormente se convirtió en el centro maderero del país, siendo hoy el tercer productor de papel de Chile con la fábrica maderera y papelera de Arauco, Celulosa Arauco y Constitución (CELCO) al frente.

17 Localidad del borde costero de la VIII región del Bio Bio, perteneciente a la provincia de Arauco, con una población de 600 habitantes. la población afectada. De igual manera, se justifica el interés de ambos casos, por ser localidades donde el PR-MINVU contempló el desplazamiento de una mayoría de la población tras la justificación de la necesidad de cualificar áreas de protección costeras frente a futuros tsunamis, parque de mitigación ${ }^{18}$, condición que dificultó la recuperación de la memoria del barrio, y en la mayoría de los casos llevó a cambiar las relaciones colectivas entre familiares y vecinos.

Constitución, situada en la desembocadura del río Maule, supone un caso controvertido. Dados los daños provocados por el tsunami en la parte antigua de la ciudad, la posterior deslocalización de la mayoría de la población afectada y la alta participación del sector privado en la planificación de la reconstrucción, no sin intereses directos en la ciudad ${ }^{19}$. En cuanto a los antecedentes locales, destacaríamos el crecimiento incontrolado de la ciudad en las últimas décadas a partir de la expansión maderera. Crecimiento que se produjo hacia los cerros, arrasando la foresta y generando graves

18 En los planes PRES de ambas localidades se proyectó la construcción de un área de protección en el borde marítimo o fluvial de desembocadura, que obligó al desplazamiento de la población a otros barrios o sectores de la localidad.

19 “La alianza público-privada, en general, carece de una integración robusta; por un lado, los privados, diseñan proyectos, y por el otro, el sector público los financia...La ausencia del municipio en el proceso es preocupante" (Imilán, Pino, Fuster, González, y Larenas, 2015, p. 78). 
problemas de comunicación además del riesgo por los numerosos casos de asentamientos espontáneos e ilegales que ocuparon las cuencas de los arroyos.

En el caso del sector de Llico, por ser una localidad más expuesta al océano y muy pequeña, esta fue arrasada casi en su totalidad. Durante el primer reconocimiento realizado por este proyecto (2013), existían viviendas que no habían sido incluidas en el censo realizado por el PR-MINVU ${ }^{20}$, y sin embargo, el estado de las mismas era más precario que las propias viviendas prefabricadas mediaguas cedidas por el mismo, ya que no contaban con luz ni agua, además de la falta de una red de tratamiento de aguas negras en todo el pueblo, según la información dada por los vecinos (Prieto, 2014).

Antes de continuar es necesario contextualizar mínimamente la situación del país en el tiempo de la reconstrucción. El terremoto tsunami acontece en febrero de 2010. Recientemente se habían celebrado los comicios presidenciales, lo que se entiende reafirmó al incipiente Gobierno ${ }^{21}$ en el compromiso de gestión y finalización de un PR-MINVU en el transcurso de los cuatro años de legislatura.

20 En este caso, a los subsidios de viviendas del Plan de Reconstrucción se sumaron los subsidios comunes de viviendas programadas por el Gobierno y que no habían sido resueltas aún.

21 Los comicios presidenciales se habían celebrado poco antes, con el resultado a favor del Partido Renovación Nacional, y el posterior nombramiento del presidente Sebastián Piñera.
La situación económica del país era propicia ${ }^{22}$, aunque a pesar de esta buena situación económica, la situación social no era nada prometedora, con altos índices de desigualdad en su población y una falta de equidad de género ${ }^{23}$, la tasa de incidencia de la pobreza era del 22,2\% en 2011 bajando al $14,4 \%$ en 2013. El INB per cápita, que nos relaciona el PIB con la población a mediados del año en cuestión, \$10.730 en 2010 y subiendo $\$ 15.230$ en 2013, ambos por debajo del índice medio de los estados de la OCDE.

Por otra parte, y aunque es conocida la condición de riesgo en el país a siniestros de esta índole, no existía un desarrollo de normativas y gestiones preventivas "el estado del arte en cuanto a la gestión del riesgo en Chile, en relación con los instrumentos de planificación territorial... está todavía en proceso" (Tapia, 2014, p. 47).

No existía un organismo interdisciplinar con participación de los diferentes ministerios implicados que aglutinara los conocimientos de las diferentes variables físicas, ambientales y socioeconómicas, concernientes a los sismos, afectando a normativas y ordenación territorial permitiendo la descentralización a las administraciones locales (Delamaza,

22 Con un crecimiento del PIB del 5,8 \% en 2010 bajando contenidamente hasta el 4,3 \% del año 2.013, según el Grupo del Banco Mundial. http://datos.bancomundial.org/indicador/NY.GDP. MKTP.KD.ZG.

23 Según uno de los principales indicadores Gini (http://datos.bancomundial.org/pais/chile). 
2004; Huerta, 2000). Las comunidades no cuentan con presupuesto y autonomía suficientes para la gestión de planeamientos y desarrollo de planes reguladores intercomunales o comunales.

En este contexto, se produjo el terremoto y la respuesta del Gobierno de Chile con el PR-MINVU, y una amplia participación desempeñada por el sector privado (Ley 20.444 de 23 de julio de 2010) ${ }^{24}$, a través de donaciones o aportaciones (Contreras y Beltrán, 2015) sobre todo en los programas de reconstrucción territorial, urbana y patrimonial.

El Programa Transitorio de Aldeas, dotaba de un contenedor prefabricado tipo mediagua ( 6 por 4 metros), como vivienda temporal para la población damnificada a la espera de su vivienda definitiva. Normalmente, el asentamiento de las aldeas se llevaba a las áreas libres periféricas y no afectadas por la catástrofe, aunque en algunos casos como en la aldea La Poza en la orilla del Maule y por petición de los afectados, se ubicó en sitio propio ${ }^{25}$. Estos asentamientos se dotaban en paralelo de otros apoyos destacando el programa de apoyo de reconstrucción psicosocial de los primeros años.

24 Ley 20.444, publicada en el D.0. de 28.05.2010 -y actualizada al 8 de febrero de 2012-, que "Crea el Fondo Nacional de la Reconstrucción y Establece Mecanismos de Incentivo Tributario a las Donaciones Efectuadas en Caso de Catástrofe". http:// www.sii.cl/pagina/jurisprudencia/legislacion/complementaria/ ley_20444_crea_fondo_nacional.doc

25 Denominación dada a las localizaciones que ocupaban el suelo que tenían antes de la catástrofe.
En la figura 1, se muestran planimetrías de llenos (edificaciones en negro intenso) y vacíos (en blanco), de Constitución y Llico antes del tsunami con la representación del alcance del oleaje en 2010 y la destrucción de las edificaciones, También se especifica la ubicación de las Aldeas de Emergencia (identificadas con un círculo), así como la nueva planificación o reconstrucción de nuevos condominios, con el fin de facilitar una imagen general del grado de afectación y algunas de las actuaciones derivadas, como fue la deslocalización.

En la ciudad de Constitución se habían creado cinco aldeas (Contreras y Beltrán, 2015). Entre las registradas tenemos la aldea Antofa ${ }^{26}$, un asentamiento ubicado en la periferia de la ciudad, en los cerros por encima del Cementerio, creado sobre todo para las familias residentes del edificio céntrico colapsado Francisco Mesa Seco (figura 2). Se entregaron 20 mediaguas, sin divisiones ni revestimientos, con instalación de agua potable, una sede donde se hacían las reuniones con el MINVU, y la colocación posterior de baños químicos y un contenedor con duchas y baños. Al poco tiempo, se habilitó una lavandería por petición de la población

26 Sitio en Calle s/n nro. 40 arriba de la escuela Martín Abejón, 19 familias. El número de familias de esta y otras aldeas de emergencia se ha extraído de las fichas descriptivas de aldeas por región 2011, publicado por el MINVU en http://www.minvu.cl/ opensite_20100909103844.aspx y http://www.minvu.cl/opensite_20100909104019.aspx>. 


\section{FIGURA 1. CLAVES EN LOS PROCESOS ESPACIALES ESPONTÁNEOS EN ALDEAS.}

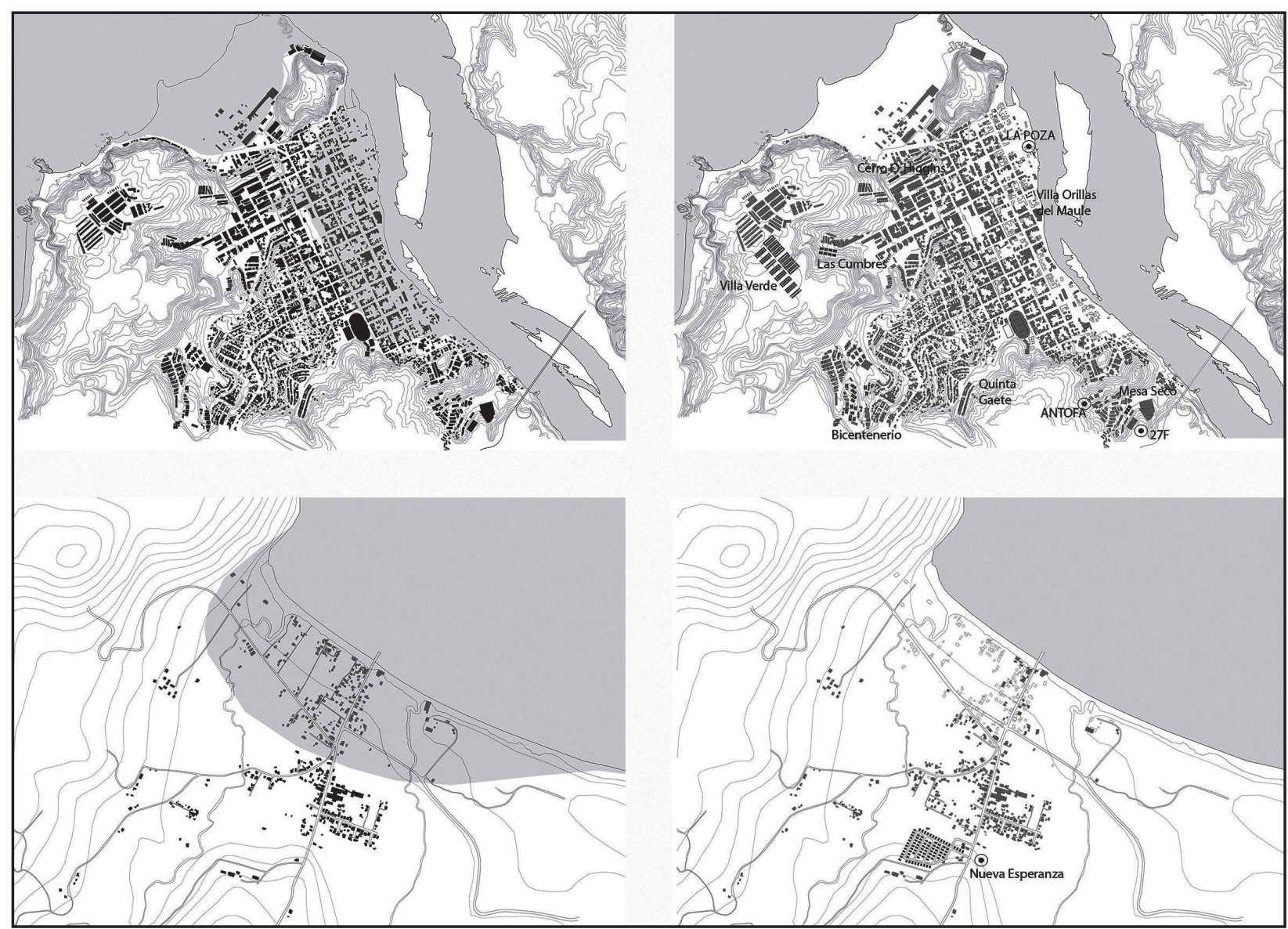

Arriba, derecha: Constitución, afectación terremoto/tsunami 2010.

Arriba, izquierda: Constitución, previsiones y estado reconstrucción 2013.

Abajo, derecha: Llico afectación terremoto/tsunami 2010.

Abajo, izquierda: Llico, previsiones y estado reconstrucción 2013

Fuente: Realización propia, colaboración R. Estrada y L. Carreño. 
FIGURA 2. ESPACIO PARA EL ENCUENTRO. ALDEA ANTOFA. CONSTITUCIÓN. AGOSTO 2013.

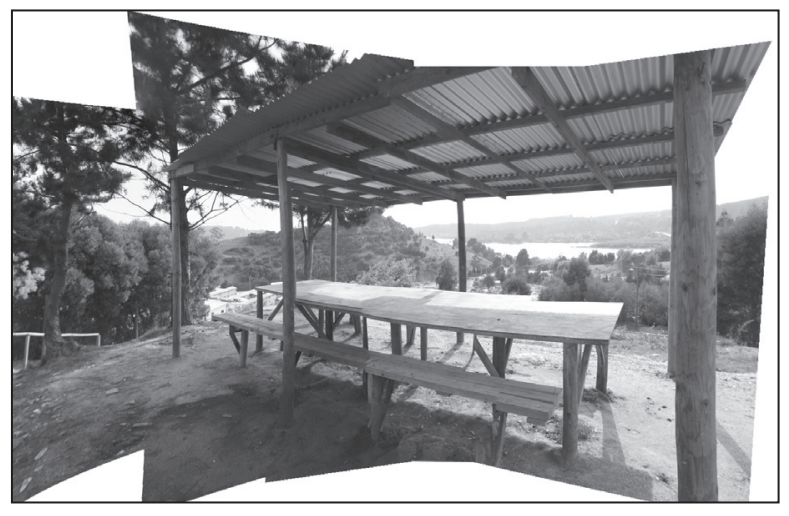

Fuente: Realización propia.

al MINVU. Las familias fueron las encargadas de terminar las viviendas en cuanto a revestimientos, crear las divisiones y agrandarlas comprando otras mediaguas, si lo necesitaban. Una vez que recibieron la vivienda definitiva subsidiada, 17 de las familias se trasladaron a los departamentos de la IV etapa de Centinela y vendieron las mediaguas. Las otras tres familias que permanecían allí en agosto de 2013, estaban esperando la terminación del proyecto Villa Verde de viviendas unifamiliares (Prieto, 2014, p. 3).

La exploración de los procesos espaciales espontáneos de apropiación surgidos en estas aldeas, ha permitido desvelar la existencia de lo que denominamos espacios de oportunidad, llamados así por ser intersticios no previstos para su uso, que aparecen entre las mediaguas, junto a árboles o aprovechando una pequeña loma, pero que más allá de los inconvenientes propios de las condiciones de las unidades de prefabricados. Según los comentarios de sus habitantes, eran espacios que les proporcionaron un bienestar en cuanto a la experiencia grupal y de entorno. En la imagen expuesta se puede observar la disposición de un comedor colectivo con vistas, por ejemplo, fruto del aprovechamiento de una cornisa libre, de un entorno natural y de un espacio que ha permitido la construcción de un lugar para uso de todos. Se podría hablar, tras el análisis de esta apropiación, de la importancia del paisaje (desde su componente medioambiental además de la contemplación) como aportación cualitativa al espacio colectivo. El recuerdo del desastre despierta la necesidad de afectividad, de comunicar y de compartir de la condición humana, que en otras circunstancias no se daría con esta evidencia. Es la población misma, con su sabiduría de generaciones, la que improvisa redes y crea espacios para el encuentro, como en estos casos, entendiéndose por tanto la necesidad de crear infraestructuras flexibles que permitan el desarrollo de hábitos cotidianos colectivos, hábitos que puedan transmitir la sensación de permanencia y seguridad, haciendo imperecedero lo transitorio. 
FIGURA 3. ENTORNO ALDEA LA POZA. CONSTITUCIÓN. AGOSTO 2013.

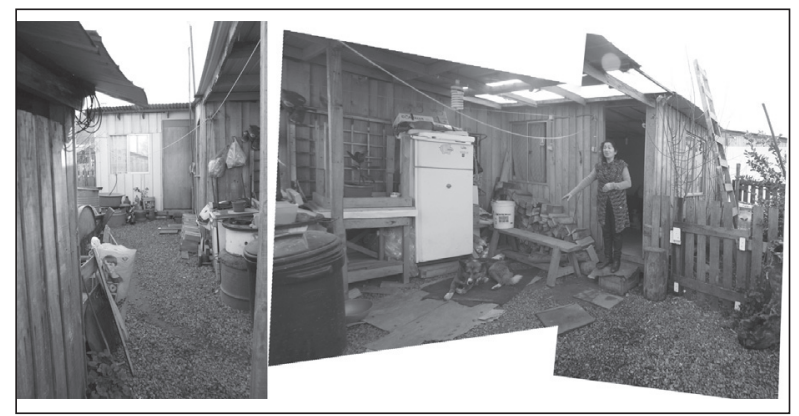

Fuente: Realización propia.

Aunque, en algunos casos, solo la huella de lo que había sido un jardín a la entrada de la mediaguas, con dos bancos y sillas, refería la necesidad de expandir la casa como amago de invitación a la relación colectiva que tenía la población y que normalmente no fue resuelto en las propuestas departamentales en altura.

En la aldea La Poza, creada para las familias del borde costero y situada en el mismo sitio donde las viviendas originarias fueron arrasadas conservando el mismo nombre del antiguo barrio, pudimos observar que quedaban pocas familias, todas a la espera de la construcción del proyecto Villa Orillas del Maule ${ }^{27}$ (figura 3). La simple observación denota las fuertes transformaciones realizadas por los usuarios en las mediaguas originarias y en sus entornos. Estas transformaciones no solo respondían a mejoras técnicas, como impermeabilizaciones, aseos, y otras distribuciones, sino que suponían procesos espaciales basados en apropiaciones simbólicas que pretendían devolver la memoria de elementos, usos y procederes del entorno doméstico recordado y perdido. Los espacios se iban creando con la ocasión de los vacíos que quedaban entre las mediaguas, entornos protegidos que van dando pie a la casa extensiva por su capacidad de extender lo doméstico más allá de sus propios límites, cuestión que se manifestaba en el quehacer cotidiano de la mayoría de las familias.

Las restantes aldeas 27F (calle Eusebio Ibar, sector Centinela, 39 familias), Caleta Pellines (Caleta Pellines Viejo, 29 familias) y Puertas Verdes (kilómetro 8 camino San Javier, 170 familias) ya casi desaparecidas en nuestra visita, con la población trasladada al proyecto Bicentenario, situado en el barrio del

27 "La perseverancia de la agrupación de vecinos permitió la reconstrucción de sus viviendas en un terreno cercano a la ubicación original, empero, frente al río. Este caso es excepcional en el contexto de las relocalizaciones en Constitución, implicó un rediseño del parque de mitigación, el proyecto más relevante del pres" (Imilan et al., 2015, p. 47). 
mismo nombre donde se realizaron las primeras y más numerosas reubicaciones de familias.

En el sector de Llico, solo se creó una única aldea Nueva Esperanza (29 familias). En la visita se comprobó la existencia de un mayor número de prefabricados, 100 familias aproximadamente esperaban el subsidio de la vivienda y la mayoría procedía de viviendas del sector costero (figura 4). La aldea se ubicó junto al cerro, lejos de la costa. Se entregó una sede por el MINVU para las reuniones vecinales. Las ayudas se fueron solicitando en beneficio del total de la población y en comparación con la inversión privada (relacionada por habitante y sector dañado) otorgada en Constitución, aquí fue mínima, construyeron en la aldea una lavandería (empresa ARAUCO) (figura 5), el invernadero (FOSIS), una sede mayor (CÁRITAS Chile), chimeneas para todas las mediaguas y una pista de fútbol.

Analizando los usos y significados de los espacios intersticiales en estas aldeas, se observa la inestabilidad permanente del espacio, en cuanto al cambio según los tiempos del uso y del significado del propio espacio, se podría entender que el sentido de habitabilidad dado al espacio se ha desprendido de la espacialidad misma y se ha convertido en temporalidad. El tiempo da nombre al espacio, en cuanto que es el momento del día el que obliga a un uso u otro; zona de recreo porque es la hora de juego, área de comedor porque es la hora de comer, etc.
Diferente surge esta posibilidad cuando nos referimos a los espacios programados de los nuevos condominios, delimitados y obligados por la existencia o no del mobiliario, equipamientos convencionales y formas que los convierten en solo aptos para un uso determinado de antemano o, en ocasiones, tan solo son pura estética imposibles de usar. Sin embargo, en los espacios intersticiales de las aldeas se superponían los tiempos y los usos, ofreciendo un carácter plural y complejo a los entornos.

Pensar en el carácter de la infraestructura de lo común está en desvelar la cualidad de estos intersticios, pues son espacios hervideros de acontecimientos superpuestos, invadidos por la extensión de tareas domésticas que antes eran individuales como el lavado de la ropa y que ahora por necesidad o elección, se han convertidos en tareas colectivas y han creado espacios compartidos (figura 5), lugares improvisados para el encuentro (como también observamos en el condominio de Bicentenario, en la parte derecha de la imagen), espacios efímeros por la capacidad de adaptación a nuevas situaciones (Buci-Gluksmann, 2006).

También aparece junto a los espacios domésticos, otros espacios para la siembra, el huerto, como parte de una colectividad compartida, en la aldea Antofa (figura 6), un programa espontáneo, de uso sostenible, convierte un trozo de monte en 
FIGURA 4. ARRIBA, ALDEA NUEVA ESPERANZA. ABAJO, VIVIENDAS NUEVA ESPERANZA. LLICO, AGOST0 2013.

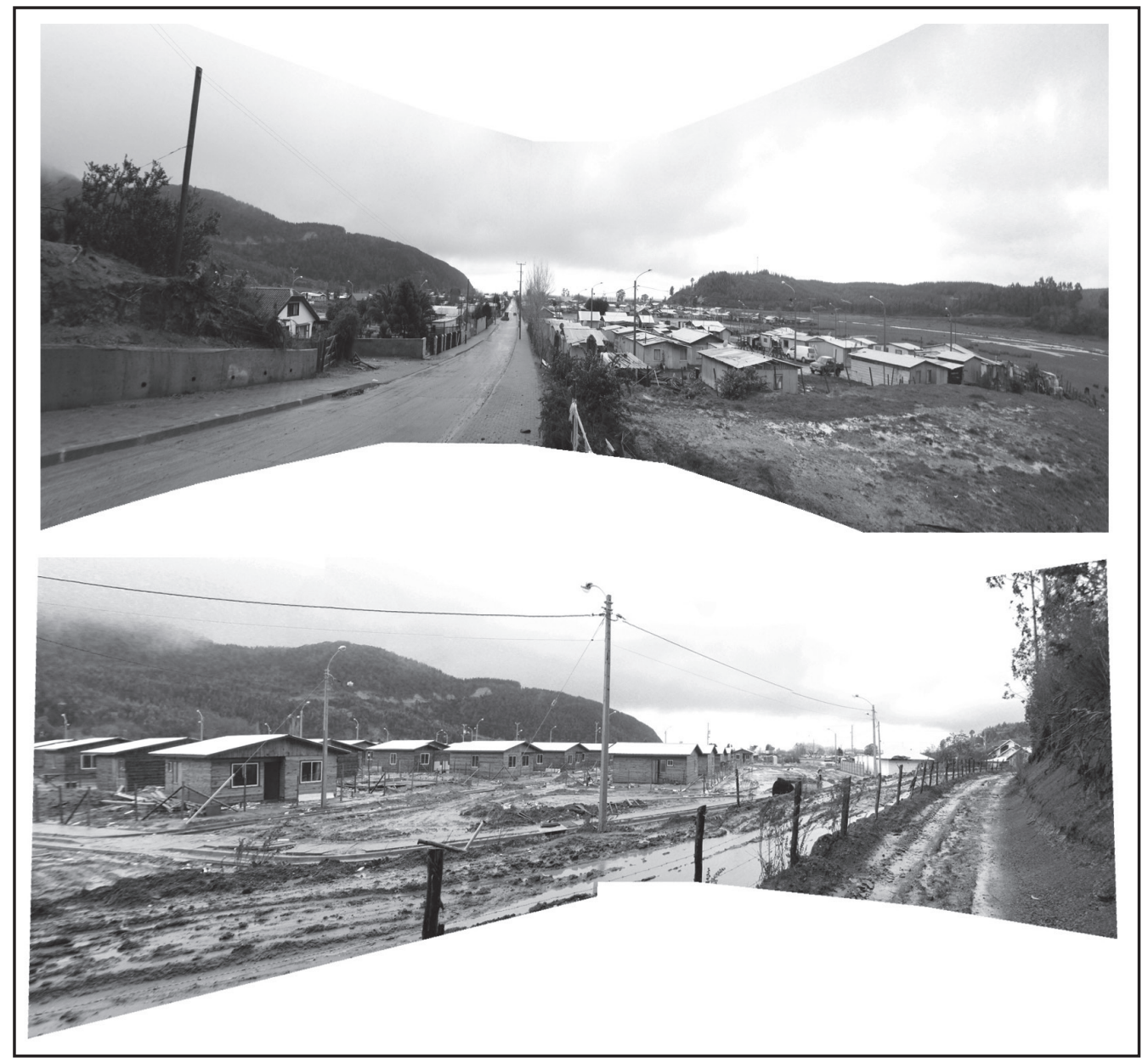

Fuente: Realización propia. 
FIGURA 5. ESPACIO INTERIOR COMPARTIDO EN LA ALDEA NUEVA ESPERANZA, LLICO, 2013. ESPACIO PÚBLICO EN BICENTENARI0, 2015.

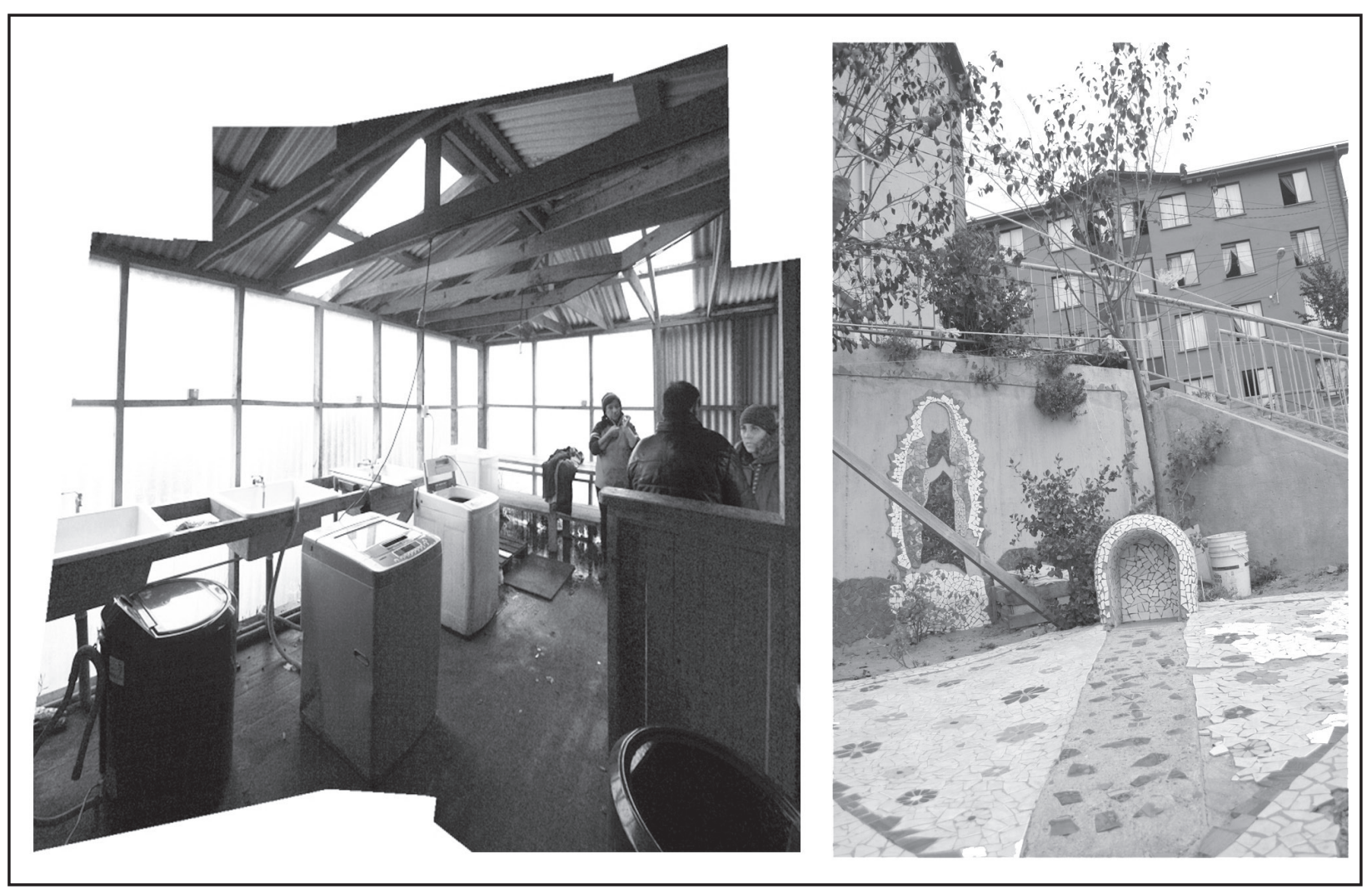

Fuente: Realización propia. 
FIGURA 6. ARRIBA, HUERTO URBANO EN EL ENTORNO DE LA ALDEA. ABAJO, VEGETACIÓN Y APROPIACIONES EN LOS EXTERIORES DE LA VIVIENDA, ALDEA ANTOFA, CONSTITUCIÓN, AGOSTO 2013.

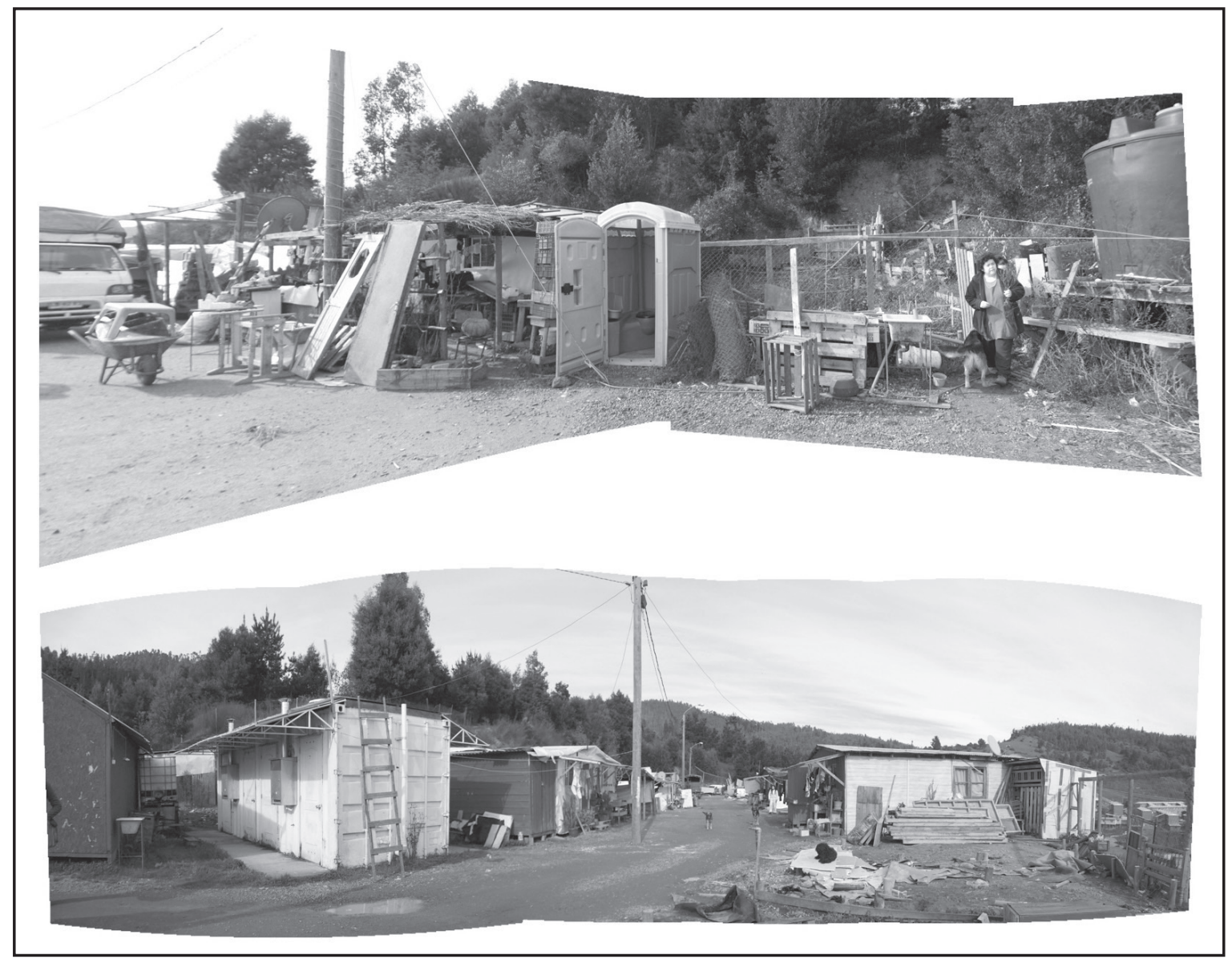

Fuente: Realización propia. 
una huerta urbana, recuperando no solamente la capacidad de un recurso alimentario, sino acercando la cotidianeidad de la vida urbana a una ecología con el medio.

Según las percepciones de sus habitantes, estos espacios intermedios son eminentemente lugares de encuentro, no son productos de una charla ocasional o resultado de interacciones urbanas entre extraños. Son realmente los espacios que definen y son definidos por el encuentro lúdico, el juego y la conversación entre la colectividad. Estos espacios intermedios son el verdadero lugar de desarrollo de la actividad social. Frente a las calles vacías que encontramos en muchos de los condominios de los departamentos reconstruidos, estos espacios muy al contrario, se encuentran llenos de personas y actividad, donde prolifera la comunicación personal, lingüística y afectiva, son espacios complejos que fomentan la conciencia del grupo, incrementando las relaciones afectivas (Durkheim, 1996) definiendo la estructura social que los identifica.

\section{Espacios colectivos y movilidad sostenible}

La tercera línea de acción propuesta en origen por el PR-MINVU (MINVU, 2011, p. 6), se dirigía a la escala urbana y territorial, enunciada como Programa Territorial, Urbano y Patrimonial de Reconstrucción que presuponía el planeamiento de aquellos sectores urbanos de la ciudad afectados. De los diferentes tipos de planeamientos desarrollados destacamos los Planes de Reconstrucción Sostenible (PRES) por ser planes de una mayor relevancia en los casos de estudios.

En el caso de Constitución, el avance propuesto por el PRES ${ }^{28}$, relaciona en porcentaje las infraestructuras en general y equipamientos, con un $46 \%$ del total del presupuesto del mismo ${ }^{29}$, que no está nada mal, aunque si se profundiza en estas partidas se observa que aproximadamente el $68 \%$ de este total está dirigido a la zona costera, el 18\% aproximadamente al equipamiento en la zona centro y tan solo el 13,57\% aproximadamente a los

28 PRES-CONSTITUCIÓN. Plan Maestro de Constitución, $4^{\text {a }}$ edición. 2011. Desarrollado por Forestal Arauco, Arup, Elemental, la Universidad de Talca, la Fundación Chile, la I. Municipalidad Constitución, la Intendencia y Seremi VII Región. http://presconstitucion.cl/>., ahora en desactivada, ver http://www.minvu. cl/opensite_20100910140027.aspx>.

29 Todos los datos expuestos en esta página están relacionados con la $1^{\text {a }}$ edición de 2010 de lo que fue la planificación del PRES-CONSTITUCIÓN. 
viales y calles de la comunicación interior en los barrios, del que tan solo aproximadamente un escaso 3\% se dedicaría a las comunicaciones de los barrios en los cerros, que por otra parte es donde ha ido el 92\% aproximadamente del total de la población damnificada.

El PRES no acomete la planificación de los grandes problemas urbanos anteriores al tsunami (Contreras y Beltrán, 2015), como verdadera oportunidad de avance y desarrollo sino al contrario, el problema de la accesibilidad se acentuará porque se verá potenciado por el incremento del sector turístico desde el propio diseño del PRES.

De igual modo, no asume la reconstrucción de infraestructuras necesarias para la movilidad y accesibilidad a los barrios altos, donde ya era difícil su acceso anteriormente y que ahora con el incremento de la población en los mismos, se hace imposible, debiendo la población asumir acciones de riesgo como la observada en la imagen (figura 7) circulando por la vía de locomoción de vehículos.

Existe una clara tendencia a la deslocalización hacia las periferias de los realojados ${ }^{30}$. Para los nuevos barrios como Vista Hermosa, Las Cumbres y

30 “Más allá del objeto vivienda, la localización de los nuevos proyectos reproduce la lógica imperante de la política urbanahabitacional chilena de desplazar la vivienda subsidiada en la periferia urbana" (Imilan et al., 2015, p. 75).
Quinta Gaete (figura 8) o para los que han sufrido un incremento de población como Bicentenario $^{31}$, como se observa en la planimetría (figura 9), donde el espesor de las flechas representadas se corresponde con el número de familias desplazadas $^{32}$ no hay prevista la infraestructura necesaria, "asimismo, se manifiesta la falta de ámbitos de encuentro, intercambio horizontal y concertación de intereses entre actores para definir lo que constituye una necesidad local prioritaria"33.

En la mayoría de los barrios la movilidad de sus vecinos es obligada, pues a la lejanía de estos nuevos barrios se unía a la falta de entramado barrial, dado que faltaba la pequeña tienda de barrio o el espacio previsto para ella, el bar, la cafetería o el restaurante, el mercado (Prieto, 2014), el pequeño parque o previsiones para áreas ajardinadas. La construcción de viviendas no ha previsto esta otra infraestructura, por lo que los desplazamientos se hacen largos, obligados y difíciles. En la mayoría de los barrios no existe el acceso directo a medios de locomoción, como taxis, colectivos o autobuses (figura 10) y el retraso en las obras que preveían infraestructuras urbanas es evidente dado que

31 "Si bien se realizaron construcciones bajo el programa de Densificación Urbana con recursos asociados a la reconstrucción, no se observa que este programa haya dado los frutos esperados". Delegación Presidencial Para la Reconstrucción, 2014, p.98.

32 En base a información INGEGROUP Consultores, abril de 2014.

33 Ibíd., p. 218. 
FIGURA 7. ACCESO ÚNICO, PEATONAL Y DE TRÁFICO RODADO AL BARRIO QUINTA GAETE, CONSTITUCIÓN, 2015.
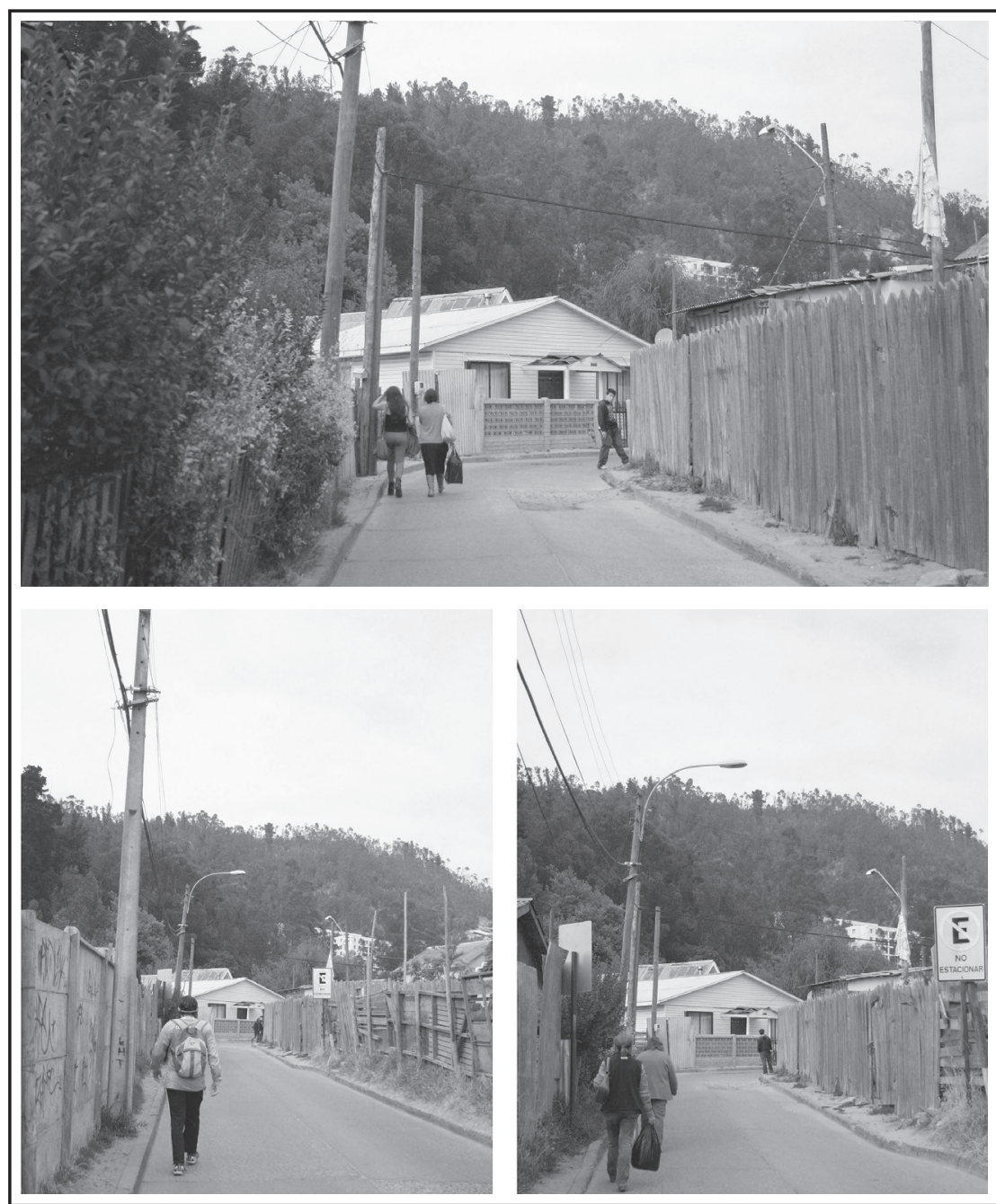

Fuente: Realización propia. 
FIGURA 8. ARRIBA, QUINTA GAETE. MEDIO, BICENTENARIO. ABAJO, VILLA VERDE. CONSTITUCIÓN, 2015.
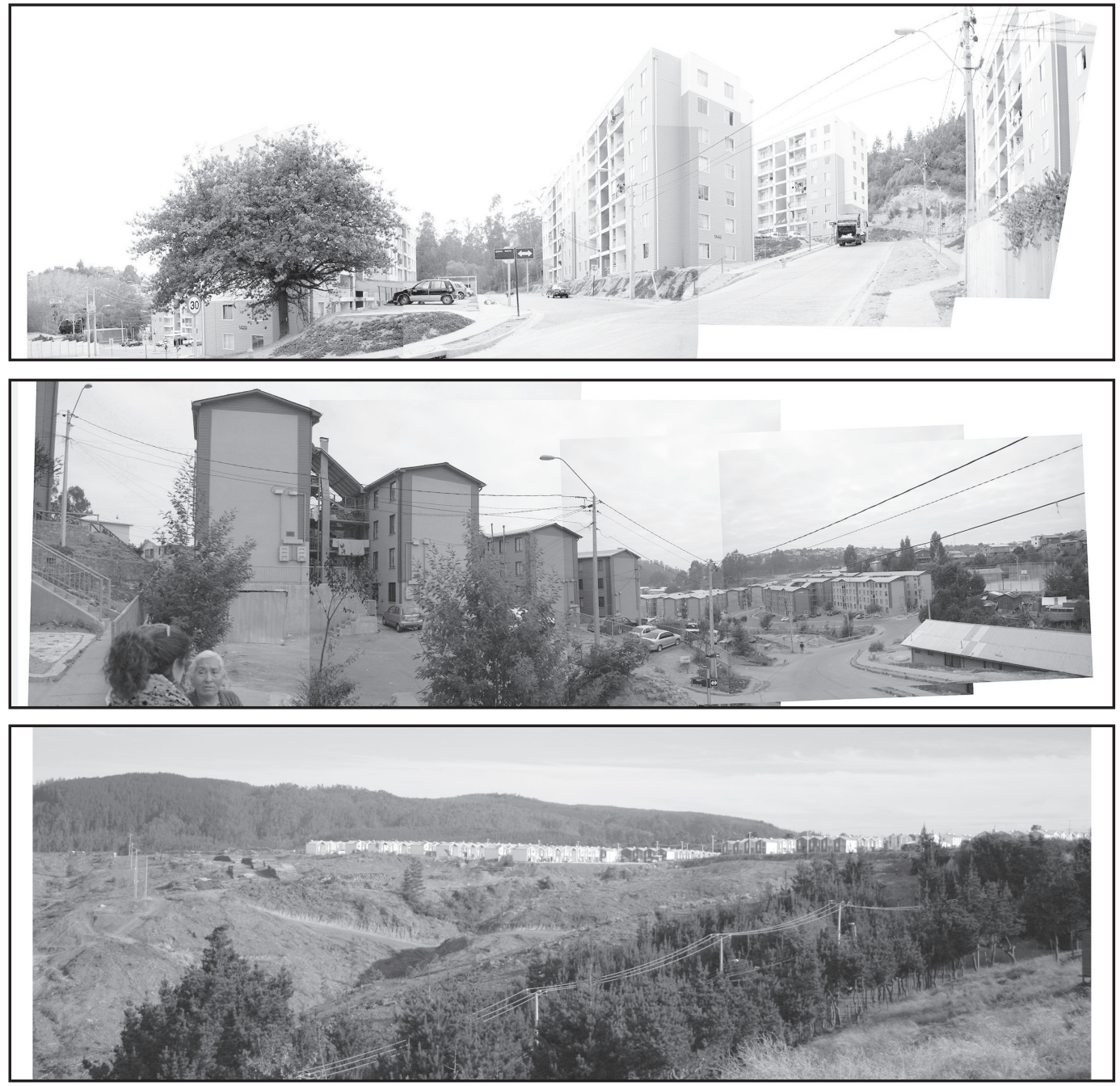

Fuente: Realización propia, colaboración R. Estrada. 


\section{FIGURA 9. DESLOCALIZACIÓN DE LA POBLACIÓN AFECTADA POR TSUNAMI, CONSTITUCIÓN, 2015.}

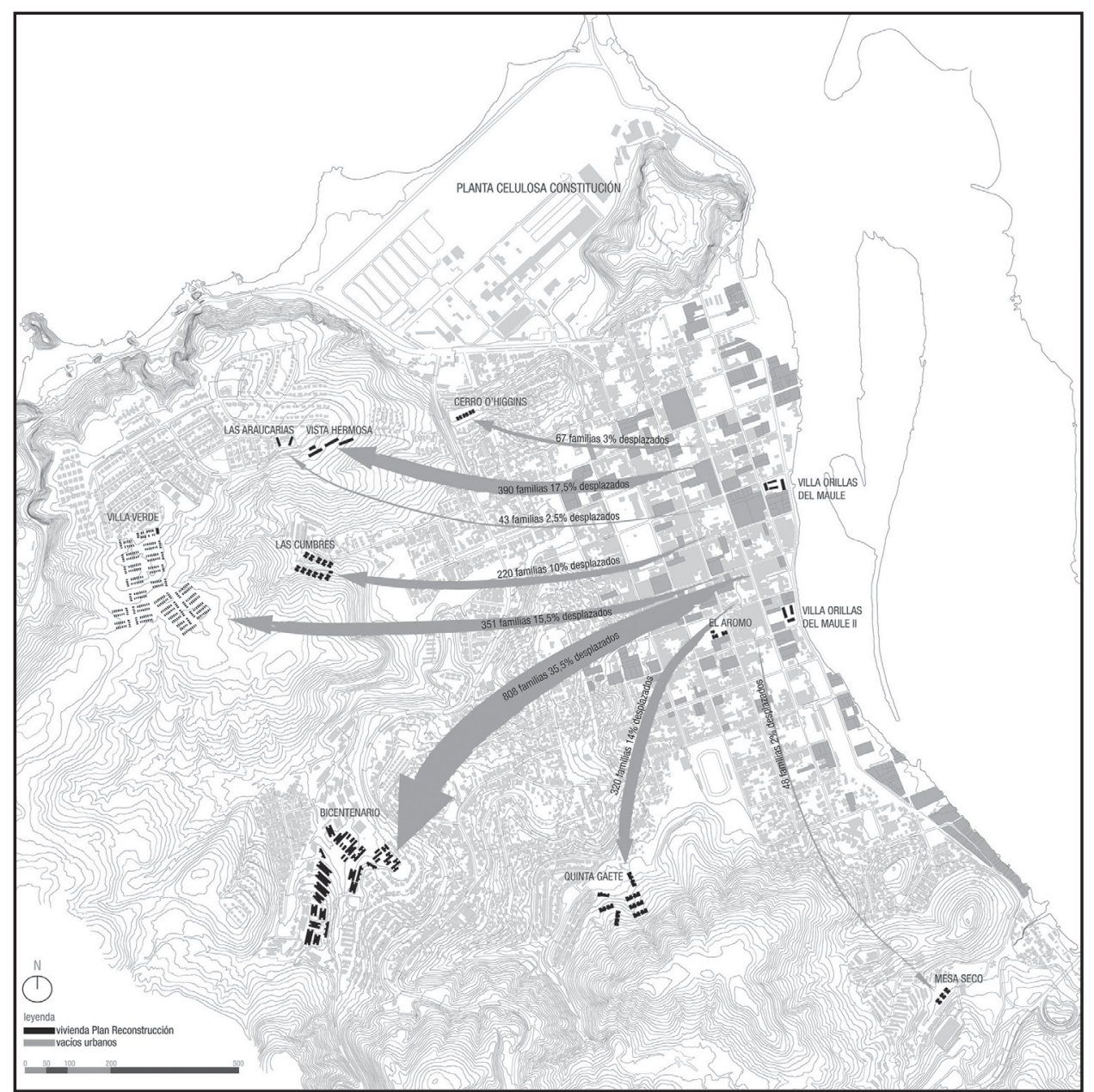

Fuente: Realización propia, colaboración R. Estrada, en base a información INGEGROUP Consultores, abril de 2014. 
FIGURA 10. ITINERARIOS DE TRANSPORTES COLECTIVOS PRIVADOS. CONSTITUCIÓN, 2015.

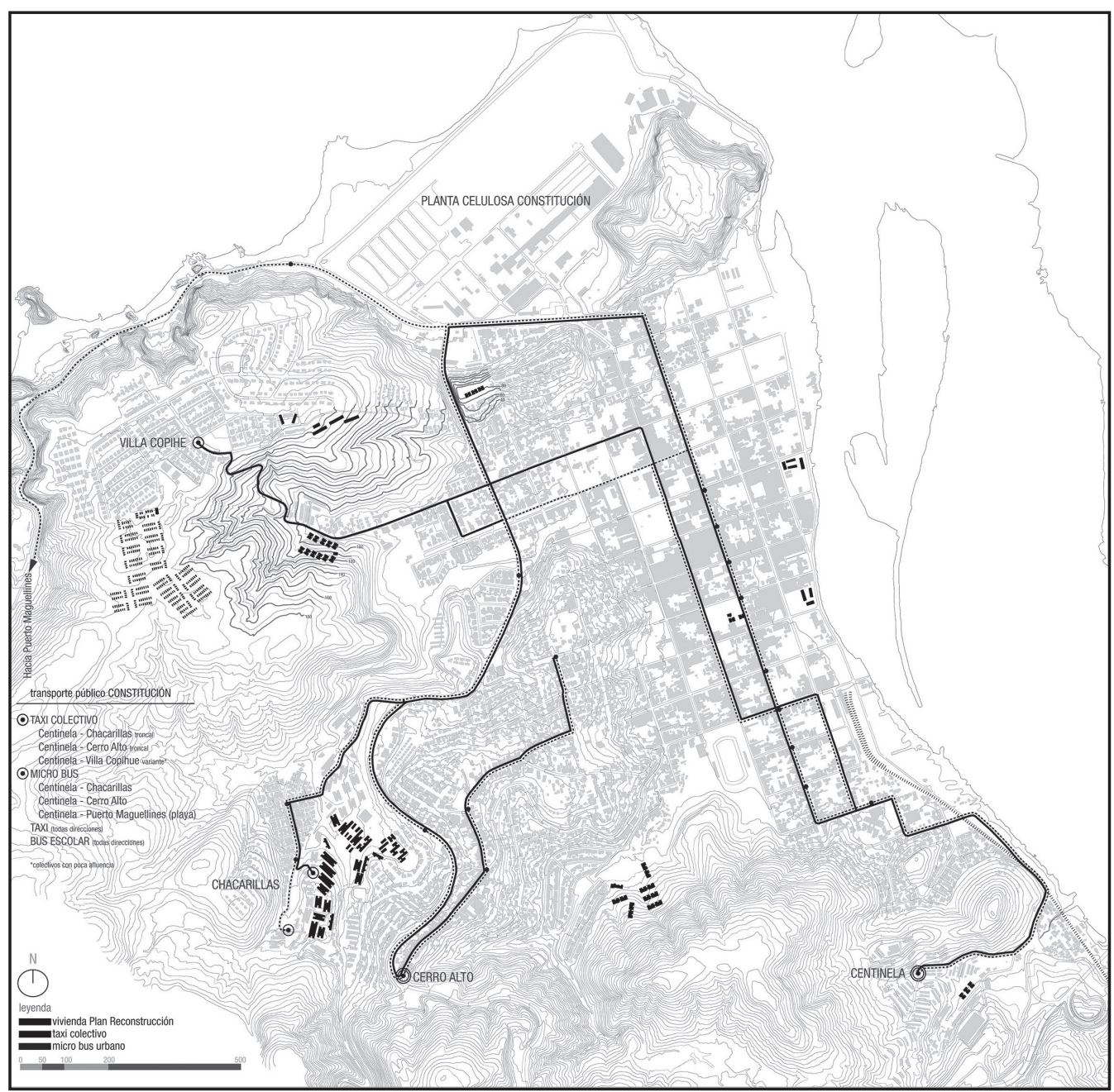

Fuente: Realización propia, colaboración R. Estrada. 


\begin{abstract}
"se exponen problemas asociados a la descoordinación interinstitucional, a la falta de fiscalización y liderazgos por parte de los gobiernos regionales cuyo efecto sobre el proceso de reconstrucción de infraestructura pública provocó también retrasos innecesarios en la ejecución de algunos proyectos, valen este mismo sentido los ejemplos ya citados respecto de Constitución y Dichato" (Delegación Presidencial Para la Reconstrucción, 2014, p. 219).
\end{abstract}

Por otro lado, en viviendas construidas no se han tenido en cuenta los elementos de vegetación y medioambientales para su entorno, infraestructuras verdes con una reforestación controlada de las especies nativas por ejemplo, combatiendo a las desforestaciones mismas realizadas para la construcción de las viviendas, como podría ser el caso representativo de Villa Verde (figura 8), con un alto grado de deforestación, pues el bosque actualmente tan solo es utilizado como recurso maderero olvidando la protección y regeneración que suponen de los suelos, descontaminación y agarre de las tierras.

En el caso de Llico, el Plan de Reconstrucción del Borde Costero, PRBC ${ }^{34}$, no contempló infraestructuras generales de crucial importancia, resueltas posteriormente de manera poco adecuada. Se modificó el proyecto de urbanización sustituyendo la pavimentación del espacio público por la construcción de una planta de tratamiento de aguas fecales a petición vecinal, por ejemplo.

Encontramos que Llico fue la gran olvidada en una reconstrucción en pro del bienestar de sus habitantes. En el momento de la investigación, se habían acometido un porcentaje mínimo de las obras relacionadas en el PR-MINVU. Los proyectos urbanos programados como la construcción de espacios públicos y la construcción y establecimientos del Bosque de Protección Arauco con el objetivo de mitigar la erosión de una nueva catástrofe, no se habían realizado, resaltando el interés de la vecindad por un proyecto de costanera frente a la propuesta de Bosque planteada como una mejor medida de protección. La mayoría de los proyectos generales de infraestructura que se han realizado han sido los dos puentes que comunicaban los pueblos costeros (Lavapiés, Llico, Tubul y Arauco) y la reposición y ampliación del camino Al Piure y ahora puede que no sea el momento de seguir

\footnotetext{
34 http://www.minvu.cl/opensite_20100910135824.aspx>.
} 
con el Plan anterior según la propia Delegación Presidencial Para la Reconstrucción ${ }^{35}$, pero en este caso habrá que comprometer otro proyecto de actuación integral que incluya infraestructuras de lo común.

\section{Conclusiones: infraestructura de lo común en la producción de barrio}

Entresacar claves que permitan proponer nuevas maneras de pensar el proyecto de infraestructura para lo común, así como evidenciar la necesidad del mismo en tiempos de emergencia, ha sido en todo momento el objetivo de esta investigación, destacando lo siguiente:

El plan de reconstrucción post-catástrofe ha de contar a medio y largo plazo con las medidas suficientes para que junto a la dotación de vivienda se resuelva la necesidad de espacios intersticiales que permitan la reunión y consigan despertar el carácter participativo de los usuarios y para ello habrán de disponer además de la cantidad, la cualidad espacial necesaria para favorecer e incentivar el uso colectivo y público. A través de la construcción del barrio, recuperar las huellas de la memoria, los lazos de familiaridad y vecindad antes existentes o promocionando los mismos.

Estos espacios deben ser accesibles, cercanos a la vivienda, a la escala humana y flexibles, con el objetivo de permitir la combinación de muy diferentes actividades y de ese modo hacerlos sostenibles en tiempo y uso. Cercanía a la tierra, que permita con facilidad la extensión de la casa, la siembra las áreas verdes y la cercanía a los espacios comunes.

De igual manera, se entiende necesario generar espacios técnicos que permitan la conversión de actividades domésticas individuales a colectivas, permitiendo de este modo disminuir costes, aumentar encuentros. Se trata de producir espacios interconectados.

A estas claves o en beneficio de alguna de ellas, se propone dotar de una técnica asequible y cercana, en cuanto a la mejora de las soluciones constructivas tradicionales con la implementación de nuevas

35 "No hay control evidente en la temporalidad de la implementación de la inversión[...] Al no existir una coordinación en la implementación de los proyectos[...] No existe una instancia política que priorice proyectos[...] Es difícil plantear la continuidad de los Planes Maestros ya que estos son más bien un conjunto de proyectos gestionados de forma sectorial" (Delegación Presidencial para la Reconstrucción, 2014, p. 68) 
técnicas de montaje (Benítez, 2013) o por ejemplo, la utilización de energías alternativas que permiten independencia, flexibilidad y sostenibilidad a los espacios.

Y por último, de manera general y considerando la escala ciudad, entender la necesidad de un urbanismo de proximidad con espacios accesibles y comunicados entre sí, para acercar y compartir todas estas claves con el resto de la ciudad.

\section{Referencias bibliográficas}

Alguacil, J. (2000). Calidad de vida y praxis urbana. Madrid: Ciudades para un Futuro más Sostenible Escuela Técnica Superior de Arquitectura. Recuperado de http://habitat.aq.upm.es/cvpu/acvpu.pdf.

Allen, S. (1998). El urbanismo de las infraestructuras: siete proposiciones. Madrid: Circo.

Anguera, M.T. (1998). Recogida de datos cualitativos. En M.T. Anguera, J. Arnau, M. Ato, R. Martínez, J. Pascual, G. Vallejo, Métodos de investigación en psicología (pp. 523-548). Madrid: Síntesis.

Benítez, S. (2013). Cerámica social: Rehabilitation Center in Lambaré, Paraguay. Arquitectura Viva, (151), 28-33.

Buci-Gluksmann, C. (2006). Estética de lo efímero. Madrid, España: Arena Libros.
Cacciari, M. (2002). Nomadi in prigione. Casabella, (705), 4-7.

Castells, M. (2000). La era de la información: economía, sociedad y cultura. Madrid: Alianza.

Certeau, M.d. (2000). La invención de lo cotidiano. México: Universidad Iberoamericana.

Chombar de Lauwe, M.-J. (1976). L'apropiation de l'espace par les enfants i precessus de socialisation. En P. Korosec (Ed.), Apropiation de l'espace (pp. 523531). Actes de la conférence de Strasbourg.

Contreras, Y. y Beltrán, M. (2015). Reconstruir con capacidad de resiliencia: El casco histórico de la ciudad de Constitución y el sitio del desastre del terremoto y tsunami del 27 de febrero 2010. Revista INVI, 30(83), 79-115. https://doi.org/10.4067/ S0718-83582015000100003.

Delamaza, G. y Fernández, M. (2004). Innovación y ciudadanía en la gestión territorial: el rol de los municipios. Santiago: Programa de Innovación y Ciudadanía.

Delegación Presidencial Para la Reconstrucción. (2014). Diagnóstico estado de la reconstrucción terremoto y tsunami 27 de febrero de 2010. Ministerio del Interior y Seguridad Pública. Gobierno de Chile. Disponible en: http://www.gob.cl/wp-content/ uploads/2014/06/Diagnostico-27-f.pdf.

Delgado, M. (2008). Lo común y lo colectivo. Barcelona, España: Universidad de Barcelona.

Debord, G. (2010). La sociedad del espectáculo. Valencia, España: Pre-Textos. 
Durkheim, É. 1996. Clasificaciones primitivas. Barcelona, España: Ariel.

Frank, L. \& Pivo, G. (1994). Impacts of mixed use and density on utilization of three modes of travel: single-occupant vehicle, transit, and walking. Transportation Research Record, (1466), 37-43.

Gatti, G. (1999). Habitando (astutamente) en las ruinas del mapa: el Aleph, la nación, los cronopios y las modalidades débiles de la identidad colectiva. Política y Sociedad, (30), 39-52. Recuperado de http:// revistas.ucm.es/index.php/POSO/article/view/ POSO9999130039A.

Hall, P. (1999). The future of cities. Computer, environment and urban systems, (23)3, 173-185. https://doi. org/10.1016/S0198-9715(99)00014-9.

Harvey, D. (1998). La condición de la posmodernidad. Investigación sobre los orígenes del cambio cultural. Buenos Aires, Argentina: Amorrortu.

Hernández Aja, A. (2009). Calidad de vida y medio ambiente urbano. Indicadores locales de sostenibilidad y calidad de vida urbana. Revista INVI, 24(65), 79-111. http://dx.doi.org/10.4067/ S0718-83582009000100003.

Huerta, M., Pressaco, C., Ahumada, C., Velasco, M., Puente, J., y Molina, J. (2000). Descentralización, municipio y participación ciudadana: Chile, Colombia y Guatemala. Bogotá, Colombia: Centro Editorial Javeriano CE JA.

Imilán, W, Pino, F., Fuster, X., González, L.E., y Larenas, J. (2015). Constitución. En: Learning from 27f: A comparative assessment of urban reconstruction processes after the 2010 earthquake in Chile (pp. 5980). Columbia Global Centers, Conicyt.

Jacobs, J. (2011). Muerte y vida de las grandes ciudades. Madrid, España: Capitán Swing.

Lefebvre, H. (2002). Critique of everyday life. Londres: Verso.

Levi, L. y Andersson, L. (1980). La tensión psicosocial: población, ambiente y calidad de vida. México: El manual moderno.

Maykut, P. y Morehouse, R. (1999). Investigación cualitativa. Una guía práctica y filosófica. Barcelona: Hurtado.

Melucci, A. (1996). Challenging codes. Collective action in the information age. Cambridge, Reino Unido: Cambridge University Press.

Ministerio de Vivienda y Urbanismo. (2009). Déficit urbano-habitacional: una mirada integral a la calidad de vida y el hábitat residencial en Chile. Santiago de Chile: MINVU.

(2011). Plan de reconstrucción Chile unido reconstruye mejor. Santiago: MINVU.

(2011). Presentación aldeas 2011. Recuperado de http://www.minvu.cl/opensite_20110325190343.aspx.

Negri, A. y Casarino, C. (2012). Elogio de lo común: conversaciones sobre filosofía y politica. Barcelona, España: Paidós.

Prieto Peinado, M. (2015). En el margen de lo urbano: apropiaciones y habitares urgentes. Sevilla, España: Editorial Universidad de Sevilla. 
(2014). Constitución 27-F. La reconstrucción en Chile como estrategia para la inversión privada. Recuperado de http://www.laciudadviva.org/ blogs/?p=28899.

Simmel, G. (1986). El individuo y la libertad: ensayos de crítica de la cultura. Barcelona, España. Península.

Soja, E., Zaro, M., y Hendel, V. (2008). Postmetrópolis: estudios críticos sobre las ciudades y las regiones. Madrid, España: Traficantes de Sueños.

Tapia, R. (2014). Terremoto 2010, Chile: evaluación de la aplicación de normativa. En Vulnerabilidades y desastres socionaturales. Experiencias recientes en Chile, (pp. 41-61). Santiago: Universitaria.

Taylor, S.J. y Bogdan, R. (1994). Introducción a los métodos cualitativos. La búsqueda de significados. Barcelona: Paidós.

Trías, E. (1991). Lógica del límite. Barcelona: Destino. 